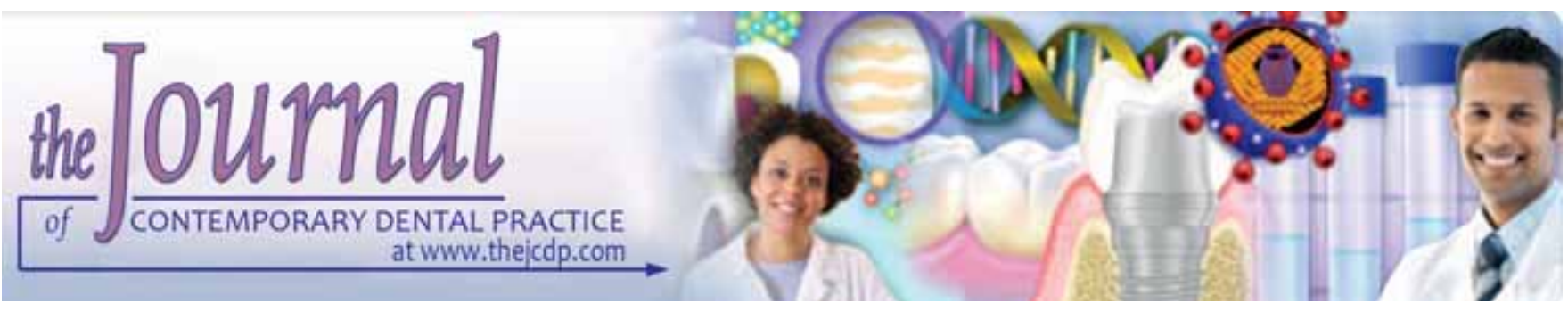

\title{
Comparative Analysis of Dimensional Precision of Different Silicone Impression Materials
}

\author{
Bader K Al-Zarea, Mohamed G Sughaireen
}

\begin{abstract}
Objectives: To investigate the accuracy of four commercial types of additional silicone impression materials (AFFINIS ${ }^{\circledR}$, Virtual ${ }^{\circledR}$, Relay 2002 CD $^{\circledR}$ and Silagum ${ }^{\circledR}$ ).

Materials and methods: The accuracy of impression material was measured indirectly by measuring three dimensions on stone cast poured from impressions of a stainless steel master model. The three dimensions on stone cast were measured at 1 hour, 2 days, 1 and 2 weeks after making the impression. Two impression techniques were used in the current study. The two-step impression technique was used for AFFINIS ${ }^{\circledR}$ and Virtual $^{\circledR}$, while single-step technique was used for Relay 2002 $C D^{\circledR}$ and Silagum ${ }^{\circledR}$ materials. Twenty impressions were made of the master cast at four different periods for each of the tested four materials with a total of 320 impressions. Two vertical dimensions and one horizontal dimension were measured on master cast using optical microscope. Statistical analysis was run to compare the mean measurements for tested casts from each impression and time interval with the master cast.
\end{abstract}

Results: No statistical significant differences were found $(p>0.05)$ in the accuracy of tested materials. There was no significant difference of master cast and impression cast means over time. Additionally, impression technique could be correlated with accuracy.

Conclusion: The tested additional silicones showed accuracy over time and they could be delayed up to 4 weeks duration without any significant changes in its dimensional stability. Silagum ${ }^{\circledR}$ impression material was the most accurate followed by Relay 2002 CD $^{\circledR}$, Virtual $^{\circledR}$ and AFFINIS ${ }^{\circledR}$.

Clinical significance: Silagum ${ }^{\circledR}$ impression material is most accurate followed by Relay $2002 \mathrm{CD}^{\circledR}$, Virtual ${ }^{\circledR}$ and AFFINIS ${ }^{\circledR}$.

Keywords: Impressions, Additional silicone, Dimensional precision, AFFINIS ${ }^{\circledR}$, Virtual ${ }^{\circledR}$, Relay 2002 CD $^{\circledR}$, Silagum $^{\circledR}$.

How to cite this article: Al-Zarea BK, Sughaireen MG. Comparative Analysis of Dimensional Precision of Different Silicone Impression Materials. J Contemp Dent Pract 2011; 12(3):208-215.

Source of support: Nil

Conflict of interest: None declared

\section{INTRODUCTION}

Fabrication of well-fitting cast restoration demands a high degree of dimensional accuracy, detail reproducibility and void-free cast poured from adequate impressions. Obtaining accurate record of the mouth is critical to ensure optimal fit and success of indirect restorations. Particularly, accurate marginal integrity will limit the chances of caries under the restoration. Dental surveys have shown that $34.3 \%$ of fixed units require replacement due to inaccurate fit and poor adaptation of the restorations. ${ }^{1}$ Multiple impression materials are existed commercially. Impression materials are classified into rigid and elastic materials. Rigid impression materials cannot be used in structures with undercuts and solely confined to edentulous cases. On the contrary, elastic impression materials can be used in areas with undercuts, edentulous, partially dentate and fully dentate patients.

Addition silicone or polyvinyl siloxanes (PS) are elastic impression materials used in fixed prosthodontics, removable prosthodontics and implant dentistry. They are characterized by excellent dimensional accuracy, ${ }^{2,3}$ ease of mix and stable characteristics. ${ }^{4} \mathrm{PS}$ was shown to have better elastic recovery and less permanent deformation than other elastomeric impression materials. PS has enough elastic recovery to permit an impression to be poured only 6 minutes after removal from the mouth. ${ }^{5}$ PS materials are based on the polydimethyl polymer, similar to condensation silicones. However, PS contains a different terminal group that is responsible for their different chemical reactions from the condensation silicones. This accounts for the improvement in the dimensional stability of its polymerization reactions.

Addition silicone materials produce excellent dimensional stability of die models made after 1, 4 and 24 hours form impression processing. ${ }^{6}$ However, some researchers found that PS and polyether elastomeric materials were dimensionally unstable over time but these 
changes were unnoticeable clinically and considered negligible. $^{7}$

The comparison of different commercial types for the same impression material was not fully understood. Therefore, this study was carried out to investigate the accuracy of four commercial types of additional silicone impression materials $\left(\right.$ AFFINIS $^{\circledR}$, Virtual $^{\circledR}$, Relay 2002 CD $^{\circledR}$ and Silagum ${ }^{\circledR}$ ) using the single-step and two-step impression techniques. Moreover, the effect of delayed poured dies on the dimensional stability of these impression materials was also investigated.

\section{MATERIALS AND METHODS}

A master model made of stainless steel was constructed (Fig. 1). The master stainless steel model contained two shouldered full crown preparations (base diameter $15 \mathrm{~mm}$, height from shoulder margin $12 \mathrm{~mm}$, shoulder width $2 \mathrm{~mm}$ and taper $7^{\circ}$ ). A custom made stainless steel tray was made to accommodate the master model (Fig. 2).

Two vertical dimensions (represented by $\mathrm{A}$ and $\mathrm{B}$ dimensions) and one horizontal dimension (represented by $\mathrm{AB}$ dimension) (Fig. 3) were measured on the master stainless steel model using traveling microscope (Titan measuring microscope, USA) (Fig. 4) capable of measuring to $0.001 \mathrm{~mm}$.Vertical and horizontal measurements were made at $10 \times$ magnification. The mean A dimension for the master stainless steel model was $11.852 \mathrm{~mm}( \pm 0.007)$, while the $\mathrm{B}$ dimension was $11.842 \mathrm{~mm}( \pm 0.004)$ and the mean $\mathrm{AB}$ dimension was $23.702 \mathrm{~mm}( \pm 0.006)$.

The accuracy of four commercial types of addition silicone was tested in the present study. These types were AFFINIS $^{\circledR}$ (Coltene, Switzerland), Virtual ${ }^{\circledR}$ (Ivoclar Vivadent, Italy), Relay 2002 CD $^{\circledR}$ (Tissidental, Italy) and Silagum ${ }^{\circledR}$ (DMG Hamburg, Germany). All materials had a cartridge dispensing system for low viscosity light body

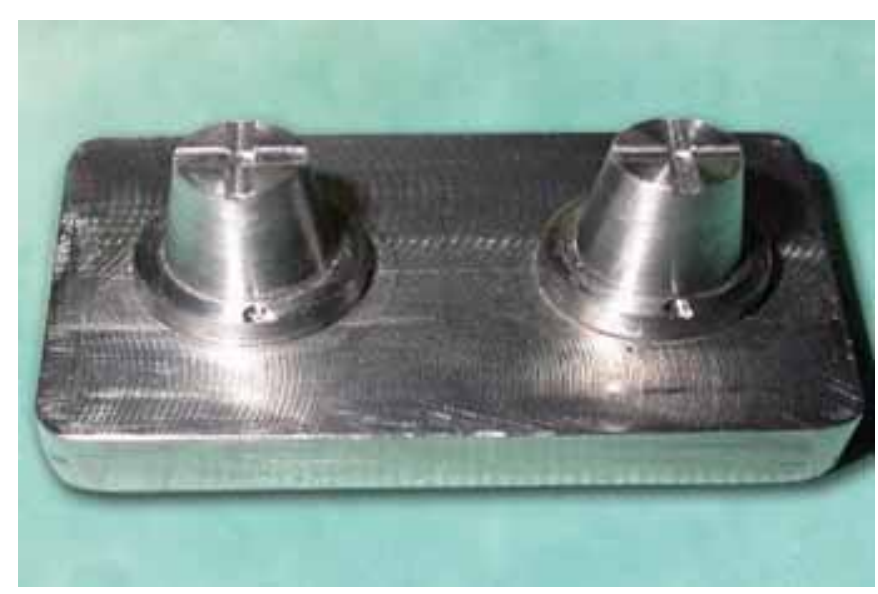

Fig. 1: Master stainless steel model containing two shouldered full crown preparation (base diameter $15 \mathrm{~mm}$, height from shoulder margin $12 \mathrm{~mm}$, shoulder width $2 \mathrm{~mm}$, taper $7^{\circ}$ ). impression materials, while the high viscosity putties needed hand-mixing procedure. All impression materials were tested in a recommended room temperature $\left(25^{\circ} \mathrm{C}\right)$ in a humidity of $50 \%( \pm 10 \%)$.

The accuracy of impression material was measured indirectly by measuring three dimensions (A, B, AB) (Fig. 3) on stone cast poured from impressions of a stainless steel master model. The three dimensions on stone cast were measured at 1 hour, 2 days, 1 week and 2 weeks after making the impression.

Two impression techniques were used in this study. Twostep impression technique was used for AFFINIS ${ }^{\circledR}$ and Virtual, ${ }^{\circledR}$ while single-step technique was implemented for Relay 2002 CD $^{\circledR}$ and Silagum ${ }^{\circledR}$ materials. Tray adhesive supplied by the manufacturer was thinly and evenly applied over the inner surface of the tray. Adhesive was allowed to dry for 15 minutes before the impression was made.

In the two-step technique, one investigator mixed by hands equal weights of putty catalyst and base using manufacturers' scoops to produce equal amounts for mixing, then the putty was loaded into the mould, and the mould was secured to the stainless steel cast model. After setting, $2 \mathrm{~mm}$ space was created into the made impression by scalpel knife and light impression was injected into the impression mould and around the abutments of the master cast model and again the impression mould was secured to master model. Concerning single-step technique, one investigator injected the light-body impression material around the reference points. Another investigator simultaneously mixed by hand equal ratio of putty catalyst and base using the manufacturers' scoops. The same investigator mixed all putties to ensure reliability of the technique. Metal mould was filled with putty and seated to the master cast model. Light body was also injected into the filled mould. All impressions were mixed according to manufacturers' recommendation time.

Twenty impressions were made of the master cast at four time periods ( 1 hour, 2 days, 1 week and 2 weeks after making the impression) for each of the tested four materials, with a total of 320 impressions. Each impression on the stainless steel model was then placed into warm water bath and maintained at $32^{\circ} \mathrm{C}$ to mimic oral temperature (American Dental Association Specification No. 19, 1977). All impressions were permitted to set in water bath for 10 minutes, exceeding all manufacturers' minimum setting times. The impressions were separated from the master cast, rinsed, dried and stored. One hour before being poured, topical surfactant (Tensilab, Zhermack, Italy) was applied on the impression surface according to the manufacturer's recommendations and allowed to dry for 5 minutes. Impressions were poured in type IV improved die stone (GC 

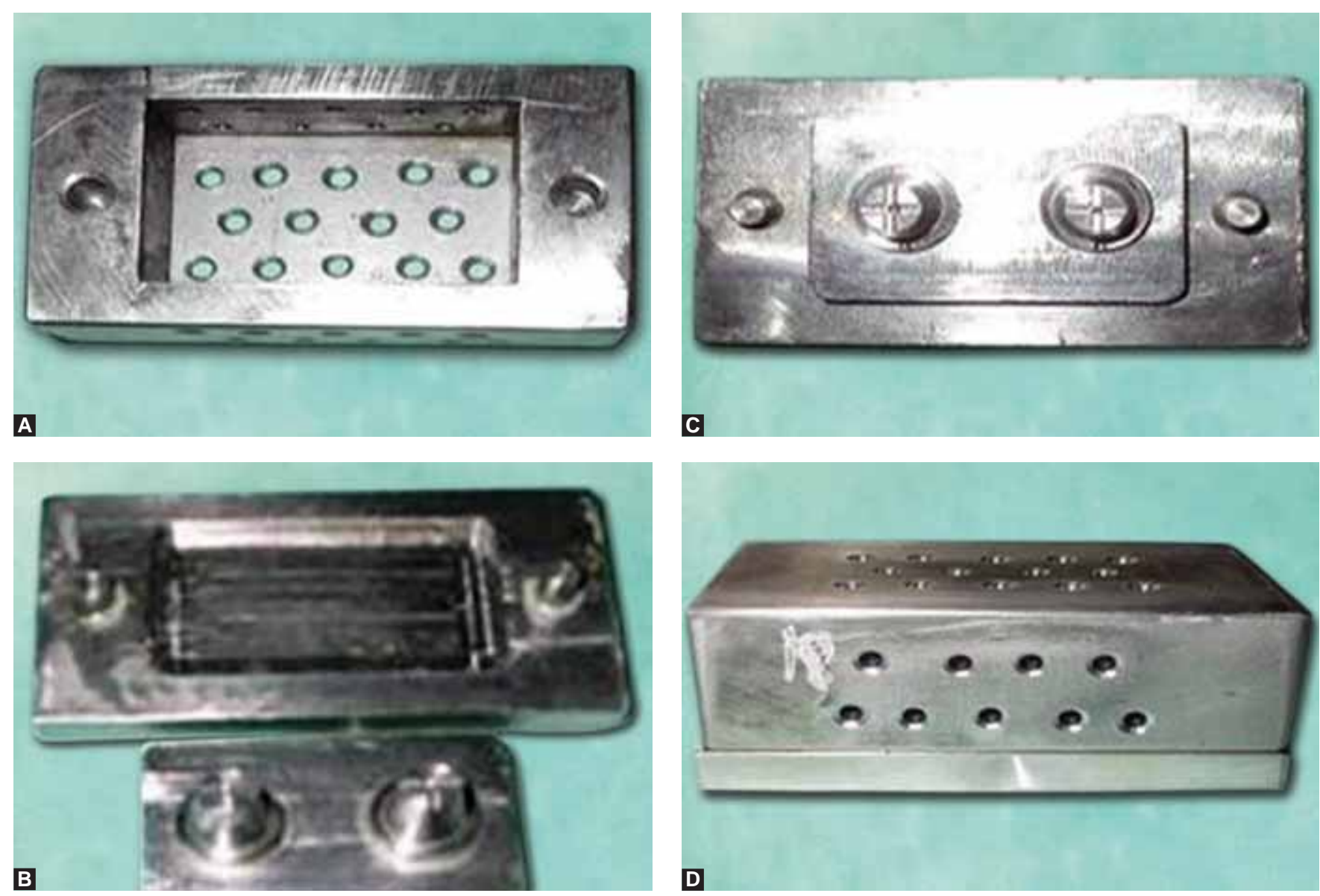

Figs 2A to D: A custom-made stainless steel tray to accommodate the master model. (A) Perforated stainless steel custom tray cover with seating channels, (B) base of the tray with locating projections and the master model adjacent to it, (C) master model in the base of the tray and (D) the tray cover over the assembly of the base and the master model

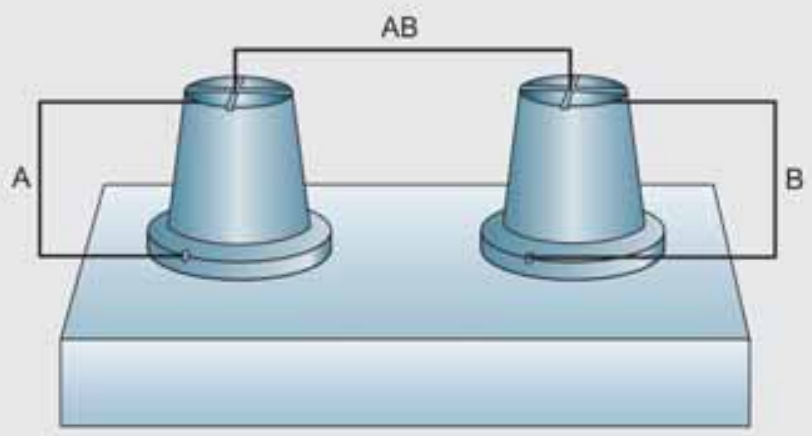

Fig. 3: Sketch of the models showing letter codes that indicate three dimensions measured on master model and stone casts. A-occlusogingival height of first abutment, B-occlusogingival height of second abutment, $\mathrm{C}$ - distance between preparations

Fujirock, Belgium; ISO 6873), mixed in a ratio of $100 \mathrm{gm}$ to $25 \mathrm{ml}$ water, initially by hand to incorporate the water, and then mechanically under vacuum for 20 seconds (Easy Mix vacumixer model 4, BEGO, Germany). All mixes were introduced into the impression using a mechanical vibrator (Vibromaster, BEGO, Germany) operating at 6000 cycles/

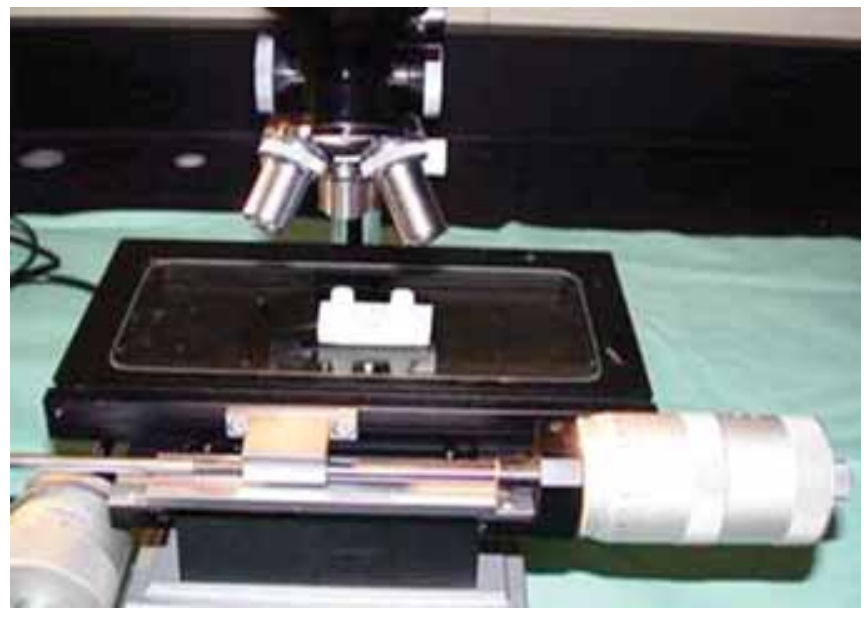

Fig. 4: One sample of the cast during measurement using traveling microscope (Titan measuring microscope)

minute and at amplitude of $0.4 \mathrm{~mm}$, at four duration time intervals according to manufacturers' instructions. After hardening the die stone, cast models were removed from the moulds.

Two vertical dimensions (A and B) and a horizontal dimension (AB) (Fig. 3) were measured on the cast models 
using traveling microscope (Titan measuring microscope, USA) (Fig. 4) at 10× magnification as above.

\section{STATISTICAL ANALYSIS}

The means, standard deviations, and mean percent differences from master cast model for vertical and horizontal dimensions were calculated for each impression material at four different time intervals. The percent differences between the measurements of the stone casts and the master stainless steel model were calculated by subtracting the mean of master cast model from the mean measurement of each die cast, dividing the difference by the mean of the master model and multiplying the result by 100. All collected data was analyzed using the SPSS (statistical package for the social sciences, version 16.0). One-way ANOVA was used to compare the dependent factors, the means for vertical and horizontal measurements with material-time interaction. For all statistical analysis the significance level was set at $\mathrm{p} \leq 0.05$.

\section{RESULTS}

\section{Vertical Dimensions}

The results revealed that for all groups in A and B dimensions, the standard deviations were less than 0.091 $\mathrm{mm}$ (Tables 1 and 2). In addition, the least percent difference was $-0.07 \%$, whereas the highest difference was $0.3 \%$. Regarding A dimension, the highest percent difference was $0.29 \%$ and was produced by AFFINIS ${ }^{\circledR}$ at one hour time interval. However, the least percent difference was $-0.07 \%$ and was produced by Silagum ${ }^{\circledR}$ at two weeks. The other two impression materials produced percent difference ranged from 0.13 to $0.27 \%$ and were presented by Relay $2002 \mathrm{CD}^{\circledR}$ and Virtual ${ }^{\circledR}$, respectively (Table 1). Regarding $\mathrm{B}$ dimension, the highest percent difference was $0.31 \%$ and it was produced by Virtual ${ }^{\circledR}$ at one hour time interval. However, the least percent difference was $-0.03 \%$ and was produced by Silagum ${ }^{\circledR}$ at two weeks time interval. The other two impression materials produced percent difference ranged from 0.06 to $0.30 \%$ and were presented by Relay 2002 CD $^{\circledR}$ and AFFINIS ${ }^{\circledR}$, respectively (Table 2).

\section{Horizontal Dimensions}

The results revealed that for all groups in $\mathrm{AB}$ dimension, the standard deviations were less than $0.09 \mathrm{~mm}$ (Table 3). In addition, the percent difference ranged from 0.32 to $0.51 \%$. The greatest range of variability was demonstrated by AFFINIS ${ }^{\circledR}$ at one hour time interval. However, the least range of variability was demonstrated by Silagum ${ }^{\circledR}$ at 2 weeks time interval. The other two impression materials
Table 1: Means, standard deviations and mean percent difference of A dimension of stone casts from master cast

\begin{tabular}{|c|c|c|c|}
\hline Groups & Mean $(m m)$ & $S D(m m)$ & $\begin{array}{l}\text { Difference } \\
\text { from master } \\
\text { model (\%) }\end{array}$ \\
\hline Master cast & 11.852 & 0.007 & - \\
\hline $\begin{array}{l}\text { After } 1 \text { hour } \\
\text { AFFINIS }{ }^{\circledR} \text { cast }\end{array}$ & 11.886 & 0.091 & 0.29 \\
\hline Virtual ${ }^{\circledR}$ cast & 11.884 & 0.07 & 0.27 \\
\hline Relay 2002 CD $^{\circledR}$ cast & 11.882 & 0.031 & 0.25 \\
\hline Silagum ${ }^{\circledR}$ cast & 11.879 & 0.08 & 0.23 \\
\hline \multicolumn{4}{|l|}{ After 2 days } \\
\hline AFFINIS $^{\circledR}$ cast & 11.884 & 0.059 & 0.27 \\
\hline Virtual ${ }^{\circledR}$ cast & 11.881 & 0.08 & 0.24 \\
\hline Relay 2002 CD $^{\circledR}$ cast & 11.876 & 0.041 & 0.20 \\
\hline Silagum ${ }^{\circledR}$ cast & 11.867 & 0.053 & 0.20 \\
\hline \multicolumn{4}{|l|}{ After 1 week } \\
\hline AFFINIS $^{\circledR}$ cast & 11.879 & 0.09 & 0.23 \\
\hline Virtual ${ }^{\circledR}$ cast & 11.875 & 0.06 & 0.19 \\
\hline Relay 2002 CD $^{\circledR}$ cast & 11.867 & 0.04 & 0.13 \\
\hline Silagum ${ }^{\circledR}$ cast & 11.859 & 0.06 & 0.06 \\
\hline \multicolumn{4}{|l|}{ After 2 weeks } \\
\hline AFFINIS $^{\circledR}$ cast & 11.871 & 0.05 & 0.16 \\
\hline Virtual ${ }^{\circledR}$ cast & 11.870 & 0.04 & 0.19 \\
\hline Relay 2002 CD $^{\circledR}$ cast & 11.867 & 0.04 & 0.15 \\
\hline Silagum ${ }^{\circledR}$ cast & 11.844 & 0.06 & -0.07 \\
\hline
\end{tabular}

Table 2: Means, standard deviations and mean percent difference of $B$ dimension of stone casts from master cast

\begin{tabular}{|c|c|c|c|}
\hline Groups & Mean $(\mathrm{mm})$ & $S D(m m)$ & $\begin{array}{l}\text { Difference } \\
\text { from master } \\
\text { model (\%) }\end{array}$ \\
\hline Master cast & 11.842 & 0.004 & - \\
\hline \multicolumn{4}{|l|}{ After 1 hour } \\
\hline AFFINIS $^{\circledR}$ cast & 11.878 & 0.082 & 0.30 \\
\hline Virtual ${ }^{\circledR}$ cast & 11.879 & 0.072 & 0.31 \\
\hline Relay $2002 \mathrm{CD}^{\circledR}$ cast & 11.871 & 0.04 & 0.24 \\
\hline Silagum ${ }^{\circledR}$ cast & 11.870 & 0.07 & 0.24 \\
\hline \multicolumn{4}{|l|}{ After 2 days } \\
\hline AFFINIS $^{\circledR}$ cast & 11.876 & 0.042 & 0.29 \\
\hline Virtual ${ }^{\circledR}$ cast & 11.873 & 0.051 & 0.26 \\
\hline Relay $2002 \mathrm{CD}^{\circledR}$ cast & 11.867 & 0.08 & 0.21 \\
\hline Silagum ${ }^{\circledR}$ cast & 11.861 & 0.044 & 0.16 \\
\hline \multicolumn{4}{|l|}{ After 1 week } \\
\hline AFFINIS $^{\circledR}$ cast & 11.870 & 0.080 & 0.24 \\
\hline Virtual ${ }^{\circledR}$ cast & 11.868 & 0.050 & 0.22 \\
\hline Relay 2002 CD $^{\circledR}$ cast & 11.859 & 0.09 & 0.14 \\
\hline Silagum $^{\circledR}$ cast & 11.855 & 0.08 & 0.11 \\
\hline \multicolumn{4}{|l|}{ After 2 weeks } \\
\hline AFFINIS $^{\circledR}$ cast & 11.867 & 0.04 & 0.21 \\
\hline Virtual $^{\circledR}$ cast & 11.862 & 0.08 & 0.17 \\
\hline Relay $2002 \mathrm{CD}^{\circledR}$ cast & 11.849 & 0.07 & 0.06 \\
\hline Silagum $^{\circledR}$ cast & 11.839 & 0.05 & -0.03 \\
\hline
\end{tabular}

produced percent difference ranged from 0.37 to $0.49 \%$ presented by Relay $2002 \mathrm{CD}^{\circledR}$ and Virtual ${ }^{\circledR}$, respectively (Table 3).

\section{The Difference of Impression Casts from Master Cast Model Over Time}

It was found that the mean dimension A of stone cast changed over time. It was found that casts obtained from 
Table 3: Means, standard deviations, and mean percent difference of $A B$ dimension of stone casts from master cast

\begin{tabular}{|c|c|c|c|}
\hline Groups & Mean (mm) & $S D(m m)$ & $\begin{array}{c}\text { Difference } \\
\text { from master } \\
\text { model (\%) }\end{array}$ \\
\hline Master cast & 23.702 & 0.006 & - \\
\hline \multicolumn{4}{|l|}{ After 1 hour } \\
\hline AFFINIS ${ }^{\circledR}$ cast & 23.824 & 0.04 & 0.51 \\
\hline Virtual $^{\circledR}$ cast & 23.82 & 0.021 & 0.50 \\
\hline Relay 2002 CD $^{\circledR}$ cast & 23.817 & 0.06 & 0.49 \\
\hline Silagum ${ }^{\circledR}$ cast & 23.824 & 0.04 & 0.51 \\
\hline \multicolumn{4}{|l|}{ After 2 days } \\
\hline AFFINIS ${ }^{\circledR}$ cast & 23.821 & 0.067 & 0.50 \\
\hline Virtual ${ }^{\circledR}$ cast & 23.819 & 0.05 & 0.49 \\
\hline Relay 2002 CD $^{\circledR}$ cast & 23.811 & 0.04 & 0.46 \\
\hline Silagum ${ }^{\circledR}$ cast & 23.794 & 0.06 & 0.39 \\
\hline \multicolumn{4}{|l|}{ After 1 week } \\
\hline AFFINIS ${ }^{\circledR}$ cast & 23.818 & 0.06 & 0.49 \\
\hline Virtual ${ }^{\circledR}$ cast & 23.811 & 0.04 & 0.46 \\
\hline Relay 2002 CD $^{\circledR}$ cast & 23.801 & 0.05 & 0.42 \\
\hline Silagum ${ }^{\circledR}$ cast & 23.784 & 0.05 & 0.35 \\
\hline \multicolumn{4}{|l|}{ After 2 weeks } \\
\hline AFFINIS ${ }^{\circledR}$ cast & 23.810 & 0.09 & 0.46 \\
\hline Virtual ${ }^{\circledR}$ cast & 23.809 & 0.06 & 0.45 \\
\hline Relay 2002 CD $^{\circledR}$ cast & 23.789 & 0.08 & 0.37 \\
\hline Silagum ${ }^{\circledR}$ cast & 23.778 & 0.09 & 0.32 \\
\hline
\end{tabular}

AFFINIS ${ }^{\circledR}$ impression had the largest dimension A means at 1 hour and 2 days with differences of 0.034 and $0.032 \mathrm{~mm}$, respectively, from the master model. On the contrary, dimension A means for Silagum ${ }^{\circledR}$ cast at 1 and 2 weeks were the least with differences of 0.007 and $0.008 \mathrm{~mm}$, respectively. Interestingly, dimension A means for Relay $2002 \mathrm{CD}^{\circledR}$ cast means were equal to the master cast mean at 2 weeks time interval of pouring the impression.

Regarding B dimension, Virtual ${ }^{\circledR}$ and AFFINIS ${ }^{\circledR}$ cast means at 1 hour were the largest with differences of 0.037 and $0.036 \mathrm{~mm}$, respectively. However, Silagum ${ }^{\circledR}$ and Relay $2002 \mathrm{CD}^{\circledR}$ cast means at 1 and 2 weeks were the least with differences of -0.003 and $0.007 \mathrm{~mm}$, respectively. After 2 weeks of pouring the Silagum ${ }^{\circledR}$ impressions, the cast means were less than the master cast mean by $0.003 \mathrm{~mm}$. Again, it became evident during the measurement that the dimension $\mathrm{B}$ of the impressions changed over time.

Regarding AB dimension, AFFINIS ${ }^{\circledR}$ cast means at 1 hour and 2 days were the largest with differences of 0.122 and $0.119 \mathrm{~mm}$, respectively. On the contrary, Silagum ${ }^{\circledR}$ cast means at one week and 2 weeks were the least with differences of 0.082 and $0.076 \mathrm{~mm}$, respectively. It was found that the dimension $\mathrm{AB}$ of impressions changed over time.

When the difference from the master model was considered over time, Silagum ${ }^{\circledR}$ remained the most distinct material throughout this study and showed the least amount of change from the master model. However, ANOVA test was used to compare the mean measurements for tested casts from each impression at different time intervals with the master cast, and no statistical significant differences were found ( $p>0.05$ ) (Table 4). Thus, time factor has no effect on the accuracy of tested impression materials up to 4 weeks duration.

\section{DISCUSSION}

Additional silicone impression materials gained popularity among patients and clinicians and this may be attributed to the fact that this kind of impression materials has an impact on the accuracy and quality of restorative treatment. To the best of our knowledge, this is the first study that investigated the different commercial types of additional silicone in terms of manufacturers' trade name to detect the difference in accuracy with regard to dimensional stability. The literature lacked such investigation of these tested impression materials.

\begin{tabular}{|c|c|c|c|c|c|c|c|c|}
\hline \multirow[t]{3}{*}{ Dimensions } & \multicolumn{8}{|c|}{ Impression material } \\
\hline & \multicolumn{2}{|c|}{$A F F I N I S^{\circledR}$} & \multicolumn{2}{|c|}{ Virtual $^{\circledR}$} & \multicolumn{2}{|c|}{ Relay $2002 C D^{\circledR}$} & \multicolumn{2}{|c|}{ Silagum ${ }^{\circledR}$} \\
\hline & Mean square & $p$-value & Mean square & $p$-value & Mean square & $p$-value & Mean square & $p$-value \\
\hline \multicolumn{9}{|l|}{ A } \\
\hline 1 hour & 2.172 & 0.357 & 2.190 & 0.355 & 9.452 & 0.167 & 2.265 & 0.350 \\
\hline 2 days & 10.473 & 0.148 & 0.048 & 0.656 & 0.269 & 0.146 & 1.080 & 0.530 \\
\hline 1 week & 2.253 & 0.384 & 2.261 & 0.347 & 0.169 & 0.405 & 0.057 & 0.454 \\
\hline 2 weeks & 2.272 & 0.347 & 0.771 & 0.361 & 0.177 & 0.379 & 0.013 & 0.480 \\
\hline \multicolumn{9}{|l|}{ B } \\
\hline 1 hour & 0.722 & 0.375 & 0.461 & 0.396 & 0.151 & 0.416 & 0.004 & 0.683 \\
\hline 2 days & 0.720 & 0.377 & 0.285 & 0.403 & 0.052 & 0.445 & 0.005 & 0.615 \\
\hline 1 week & 0.718 & 0.367 & 0.478 & 0.375 & 0.154 & 0.392 & 0.013 & 0.470 \\
\hline 2 weeks & 1.092 & 0.351 & 0.312 & 0.383 & 0.016 & 0.427 & 0.011 & 0.441 \\
\hline \multicolumn{9}{|l|}{ AB } \\
\hline 1 hour & 28.123 & 0.095 & 2.306 & 0.427 & 0.333 & 0.546 & 0.069 & 0.680 \\
\hline 2 days & 11.737 & 0.197 & 2.337 & 0.425 & 0.785 & 0.484 & 0.002 & 0.878 \\
\hline 1 week & 7.755 & 0.217 & 6.095 & 0.240 & 0.326 & 0.549 & 0.009 & 0.838 \\
\hline 2 weeks & 1.790 & 0.439 & 1.044 & 0.468 & 0.151 & 0.613 & 0.005 & 0.871 \\
\hline
\end{tabular}


The current study investigated 320 impressions of four commercial types of additional silicones, namely: AFFINIS $^{\circledR}$, Virtual ${ }^{\circledR}$, Relay 2002 CD $^{\circledR}$ and Silagum ${ }^{\circledR}$.

The null hypothesis was that in additional silicone impression materials, there is an effect of time on accuracy of such impression materials and there is no correlation between impression technique and dimensional accuracy of die models. Our study evidenced that there was no significant difference between the mean dimensions of master cast and impression casts over time. Moreover, impression techniques could be correlated with accuracy. So, the null hypothesis was clearly rejected.

For all impression materials tested, the experimental casts were generally larger than the master cast. However, Silagum ${ }^{\circledR}$ cast models at two weeks showed less measurements than master cast in vertical dimension only (A and B). This finding agrees with other studies, but with different trade types of additional silicone. ${ }^{6,8-10}$ On the contrary, some researchers reported decreased vertical dimensions in their investigations. ${ }^{2,11,12}$ Meanwhile, there was no significant difference of impression cast measurement versus master cast. But, experimental casts that were closest to master casts were preferred from accuracy point of view. Our data showed that Silagum ${ }^{\circledR}$ and Relay $2002 \mathrm{CD}^{\circledR}$ impression materials produced casts that were closest to dimension of master model at three locations ( $\mathrm{A}, \mathrm{B}$ and $\mathrm{AB}$ dimensions). This may be the result of an inherent property of the material itself or due to the effect of impression technique. Consequently, these materials can be expected to provide the most stable and reproducible impressions in a clinical practice.

Silagum ${ }^{\circledR}$ was the most accurate impression materials tested followed by Relay $2002 \mathrm{CD}^{\circledR}$, then Virtual ${ }^{\circledR}$ and finally AFFINIS ${ }^{\circledR}$. However, it should be stressed that all of these impression materials were accurate and dimensionally stable. It was observed that the dimensions of die stone casts became larger at one hour and declined gradually at two days, one week and two weeks of pouring the impression. Polymerization shrinkage and thermal changes are two factors that may affect that process. Johnson and Craig $^{2}$ suggested that the diameters of die stones are larger than that of the master cast due to the fact that the impression material contracts toward the walls of impression tray during setting. Regarding thermal changes, it is evident in this in vitro study that the made impressions were rinsed in a warm water bath $\left(32^{\circ} \mathrm{C}\right)$ to mimic oral temperature. Cooling of the impressions from this temperature to room temperature $\left(25^{\circ} \mathrm{C}\right)$ might lead to a decrease in dimensional accuracy due to high coefficient of thermal contraction of elastomeric impression materials. ${ }^{8,13,14}$
The distortion of vertical dimension and its impact on restoration margin adaptation is considered an important issue. Any impression materials and techniques that lead to a restoration of unacceptable margin must not be utilized. It is worthy to mention that distortion greater than $0.02-$ $0.04 \mathrm{~mm}$ could be used as a criterion for the judgment of clinically acceptable cast dimensional change. ${ }^{12}$ Under the circumstances, the predicted mean vertical dimension differences in margin position on the cast (A and B dimensions) for each impression material combined with time interval did not exceed $0.037 \mathrm{~mm}$ and these means were within the acceptable limit for clinically acceptable cast dimensional change. According to this criterion, all the tested impression materials may predictably have a satisfactory and an acceptable restoration margin adaptation, which is main goal of restorative treatment.

The mean cast measurements of tested impressions were compared with mean master cast measurements and no significant statistical difference in vertical and horizontal dimensions was existed. This finding is consistent with other relevant studies. ${ }^{2,4,6,7,15-19}$ Polyvinyl siloxane impression materials are considered dimensionally stable over time. ${ }^{15,16}$ Clancy et $\mathrm{al}^{4}$ found that addition silicone impression materials remained stable after four weeks of making the impression. Williams and Jackson ${ }^{6}$ suggested that addition silicone materials produced superb and dimensionally stable die models made after 1, 4 and 24 hours form impression making. ${ }^{6}$ Johnson and Craig ${ }^{2}$ suggested that repeated pours of additional silicone impression materials at 1, 4 and 24 hours did not affect its dimensional stability. Panichuttra et $\mathrm{al}^{7}$ suggested that the dimensional changes due to delayed pours were unnoticeable clinically and considered negligible. Tjan et $\mathrm{al}^{17}$ suggested that repeated pours at various time intervals did not jeopardize the dimensional accuracy of impressions made from monophasic vinyl siloxane. ${ }^{17}$ Similarly, Piwowarczyk et $\mathrm{al}^{18}$ confirmed a similar observation and reported that no significant dimensional changes could take place when the monophasic impression materials poured at two time intervals, namely: 15 to 60 and 90 minutes. Thongthammachat et al ${ }^{19}$ reported that additional silicone impression materials had an accurate stability up to 30 days. On the contrary, Tjan and Heisler ${ }^{20}$ found a contradictory opinion regarding time effect. They suggested that a significant statistical difference between impression cast measurements and master cast after repeated pours. This result could be attributed to the mixing and combining procedure of different trade additional silicone impression material. Furthermore, they claimed that this finding insignificant clinically. ${ }^{20}$ It is well-known that multiple pourings at various time intervals will produce an 
accurate and stable die models made from polyvinyl siloxane impression materials.

It is clearly evident that single-step impression technique might produce more accurate dies than two-steps technique. Silagum ${ }^{\circledR}$ and Relay $\mathrm{CD}^{\circledR}$ impressions were made using single-step technique, while AFFINIS ${ }^{\circledR}$ and Virtual ${ }^{\circledR}$ impressions were made using two-step technique. Meanwhile, the accuracy of Silagum ${ }^{\circledR}$ and Relay 2002 CD $^{\circledR}$ impression materials was superior to the others and this finding is clinically insignificant. Some investigators claimed that the accuracy of impression materials would be improved through the modification of the mixing technique. ${ }^{21-23}$ On the contrary, others found no difference could be yielded due to technique factor. ${ }^{24,25}$ Chee and Donovan $^{21}$ compared the effect of double-mix and singlemix putty/wash techniques on the accuracy of polyvinyl siloxane impression materials. The authors favored the use of double-mix technique due to the fact that single-mix technique might fail to reproduce the fine details. Similarly, Habib and Shehata ${ }^{22}$ found that the technique utilized for making the impression of elastomeric impression materials had a significant effect on the accuracy more than the material itself. In addition, Nissan et $\mathrm{al}^{26}$ compared the accuracy of polyvinyl siloxane impression materials made from single mix putty/wash, double-mix with $2 \mathrm{~mm}$ relief space and double-mix with polyethylene spacers. They found that double-mix with $2 \mathrm{~mm}$ relief putty/wash impression technique was the most stable and produced the most accurate model dies. On the contrary, Hung et $\mathrm{al}^{25}$ suggested that the accuracy of addition silicone relied upon the material itself rather than the technique itself. They reported that one-stage putty/wash technique did not differ from the dimensional accuracy from the two-stage impression technique. ${ }^{25}$ Idris et al ${ }^{24}$ found no discrepancy in the dimensional stability of addition silicone when impressions made from one-step and two-step putty wash impression techniques. As whole, the effect of mixing technique on the accuracy of impression materials is still controversial.

It is worth to mention that to obtain accurate impressions, it is necessary to follow manufacturers' instructions strictly. In single-step technique, light-body material should be mixed first and then putty should be mixed next. It is evident that putties have short working times and rapidly increase in viscosity after mixing. This necessitates the delay of mixing the putties until seating the tray in patient's mouth. This finding is also supported by Richards et al. ${ }^{10}$ Using the optical microscope, it is possible to detect irregular surfaces of the most impressions made with additional silicone after various time intervals. This might explain the rough surface of die stones poured from such impressions that were noted by Finger and Corso et al. ${ }^{14,27}$

\section{CONCLUSION}

In summary, the dimensional stability of four commercial types of additional silicones was tested when poured at 1 hour, 2 days, 1 week and 2 weeks of making the impression. The impression technique is playing a vital role in the accuracy of such materials. The detectable changes of vertical and horizontal dimensions of stone casts were evident but without any significant difference clinically. The mean dimensional changes in this study varied from -0.008 to $0.122 \mathrm{~mm}$. Silagum ${ }^{\circledR}$ impression materials were the most accurate materials throughout of this study followed by Relay 2002 CD $^{\circledR}$, Virtual ${ }^{\circledR}$ and AFFINIS ${ }^{\circledR}$. The difference of accuracy of tested additional silicones might be attributed to the inherent properties of each material and due to the impression technique.

\section{REFERENCES}

1. Phillips RW. Skinner's Science of Dental Materials (9th ed). Philadelphia: WB Saunders Co 1991:102.

2. Johnson GH, Craig RG. Accuracy of four types of rubber impression materials compared with time of pour and a repeat pour of models. J Prosthet Dent 1985;53:484-90.

3. Tjan AHL, Drent D, Whang SB, Tjan AH, Sarkissian R. Clinically oriented evaluation of the accuracy of commonly used impression materials. J Prosthet Dent 1986;56:4-8.

4. Clancy JMS, Scandrett FR, Ettinger RL. Long term dimensional stability of three current elastomers. J Oral Rehabil 1983;10: 325-33.

5. Blomberg PAH, Mahmoud S, Smales RJ, Makinson OF. Comparative elasticity tests for elastomeric (non putty) impression materials. Aust Dent J 1992;37:346-52.

6. Williams PT, Jackson DG. An evaluation of the time-dependent dimensional stability of eleven elastomeric impression materials. J Prosthet Dent 1984;52:120-25.

7. Panichuttra R, Jones RM, Goodacre C, Munoz CA, Moore KB. Hydrophilic polyvinyl siloxane impression materials dimensional accuracy, wettability and effect on gypsum hardness. Int J Prosthodont 1991;4:240-48.

8. Lacy AM, Bellman T, Fukui H, Jendresen MD: Time-dependent accuracy of elastomer impression materials (II). Polyether, polysulfides, and polyvinylsiloxane. J Prosthet Dent 1981;45:329.

9. Federick DR, Caputo A. Comparing the accuracy of reversible hydrocolloid and elastomeric impression materials. J Am Den Assoc 1997;128:183-88.

10. Richards MW, Zeiaei S, Bagby MD, Okubo S, Jamshid S. Working times and dimensional accuracy of the one step putty wash impression technique. J Prosthodont 1998;7:250-55.

11. Craig RG. Evaluation of an automatic mixing system for an addition silicone impression material. J Am Dent Assoc 1985;110:213-15. 
12. Linke BA, Nicholls JI, Faucher RR. Distortion analysis of stone casts made from impression material. J Prosthet Dent 1985;54:794-802.

13. Jørgensen KD. Thermal expansion of additional polymerization (Type II) silicone impression materials. Aust Dent J 1982;27:377-81.

14. Corso M, Abanomi A, Canio JD, Zurakowski D, Morgano SM. The effect of temperature on the dimensional stability of polyvinyl siloxane and polyether impression materials. J Prosthet Dent 1998;79:626-31.

15. Craig RG. A review of properties of rubber impression materials. Mich Dent Assoc J 1977;59:254-61.

16. McCabe JF, Wilson HJ. Addition curing silicone rubber impression materials. Br Dent J 1978;145:17-20.

17. Tjan AH, Nemetz H, Nguyen LTP, Contino R. Effect of tray space on the accuracy of monophasic polyvinyl siloxane impressions. J Prosthet Dent 1992;68:19-28.

18. Piwowarczyk A, Ottl P, Büchler, Lauer HC, Hoffmann A. In vitro study on the dimensional accuracy of selected materials for monophase elastic impression making. Int J Prosthodont 2002;15:168-74.

19. Thongthammachat S, Moore BK, Barco MT, Hovijitra S, Brown DT, Andres CJ. Dimensional accuracy of dental casts: Influence of tray material, impression material and time. J Prosthodont 2002;11:98-103.

20. Tjan AHL, Heisler WH. Dimensional accuracy and bond strength of addition silicones. Am J Dent 1992;5:223-25.

21. Chee WWL, Donovan TE. Polyvinyl siloxane impression materials: A review of properties and techniques. J Prosthet Dent 1992;68:728-32.

22. Habib A, Shehata T. The effect of the type and the technique used for impression making on the accuracy of elastomeric impression materials. Egyptian Dent J 1995;41:1409-16.
23. Gelbard S, Aoskar Y, Zalkind M, Stern N. Effect of impression materials and techniques on the marginal fit of metal castings. J Prosthet Dent 1994;71:1-6.

24. Idris B, Houston F, Claffey N. Comparison of the dimensional accuracy of one- and two- step techniques with the use of putty/ wash addition silicone impression materials. J Prosthet Dent 1995;74:535-41.

25. Hung SH, Purk JH, Tira DE, Elick JD. Accuracy of one-step versus two-step putty wash addition silicone impression technique. J Prosthet Dent 1992;67:583-89.

26. Nissan J, Gross M, Shifman A, Assif D. Effect of wash bulk on the accuracy of polyvinyl siloxane putty-wash impressions. J Oral Rehabil 2002;29:357-61.

27. Finger WJ. Effect of storage and ambient humidity on accuracy of dental elastomeric impression material. Quintessence Int 1988;19:827-32.

\section{ABOUT THE AUTHORS}

\section{Bader K Al-Zarea}

Senior Specialist, Department of Prosthodontics, Faculty of Dentistry Al Jouf University, Al Jouf, Saudi Arabia

\section{Mohamed G Sughaireen}

Senior Specialist, Department of Prosthodontics, Bader Dental Center Algrayat, Saudi Arabia

\section{CORRESPONDING AUTHOR}

Bader K Al-Zarea, Jordanian Board, Faculty of Dentistry, Al Jouf University, Al Jouf, PO Box 2014, Saudi Arabia, Phone: 00966505391642, e-mail: mohannadhijawi@yahoo.com 